University for Business and Technology in Kosovo

UBT Knowledge Center

UBT International Conference

2017 UBT International Conference

Oct 27th, 3:00 PM - 4:30 PM

\title{
Using of HVDC Technology in Super Grids
}

Ines Bula

University for Business and Technology, ines.bula@ubt-uni.net

Valmira Hoxha

University for Business and Technology, valmi.hoxha@ubt-uni.net

Edin Bula

University for Business and Technology, edinbula2@hotmail.com

Follow this and additional works at: https://knowledgecenter.ubt-uni.net/conference

Part of the Bioresource and Agricultural Engineering Commons

\section{Recommended Citation}

Bula, Ines; Hoxha, Valmira; and Bula, Edin, "Using of HVDC Technology in Super Grids" (2017). UBT International Conference. 142.

https://knowledgecenter.ubt-uni.net/conference/2017/all-events/142

This Event is brought to you for free and open access by the Publication and Journals at UBT Knowledge Center. It has been accepted for inclusion in UBT International Conference by an authorized administrator of UBT Knowledge Center. For more information, please contact knowledge.center@ubt-uni.net. 


\title{
Using of HVDC Technology in Super Grids
}

\author{
Ines Bula ${ }^{1}$, Valmir Hoxha ${ }^{2}$, Edin Bula ${ }^{3}$ \\ 1,2,3 UBT - Higher Education Institution, Lagjja Kalabria, 10000 p.n., Prishtine, \\ Kosovo \\ \{ines.bula, valmir.hoxha\}@ubt-uni.net; edinbula2@hotmail.com,
}

\begin{abstract}
This paper describes the HVDC system, its organization, as well as advantages over the AC system. Implementation of this system will help to make Europe sustainable energy independent which will require a renewable generation portfolio where much of this portfolio will be fueled by wind and will be developed offshore as it is presented in this paper. To deliver this energy to European consumers will require the development of a high capacity transmission system the so called Supergrid, which will be capable of delivering this energy to Europe's load centers. In this paper also is presented, a DC connection of the wind farm with a grid on the mainland as well as the importance of building a Supergrid.
\end{abstract}

Keywords: HDVC, Super Grid, Wind farm, converter stations

\section{Introduction}

Electricity transmission of direct current with high voltage in recent years is increasingly proposed as an alternative to the existing system. The paper presents the basics of this system, as well as its advantages and disadvantages in comparison to the AC. Last year it is obvious that $\mathrm{AC}$ power links became uneconomic on long distance due to the reactive power requirements, especially underground cable networks where the cable capacitance dominates the power flow equations. DC power links have disadvantages such as requiring costly terminal equipment, but it becomes economical for large power over long distance. "Classic HVDC" based on Line Commutated Converters (LCC) using thyristors has become the norm for bulk power long distance transmission and international interconnection. The advent of modern HVDC links based on Voltage Source Converter (VSC) - using Insulated Gate Bipolar Transistors (IGBT) instead of thyristors, technology will facilitate the interconnection of offshore wind clusters with existing on shore grids and with each other. These new links will form a European Supergrid and will be developed and built using the next generation HVDC technology, installation vessels and marine generating plants. The technology enabling Supergrid will be both evolutionary and revolutionary and will include: Low loss, high power HVDC and hybrid systems; Extra high voltage undersea cables; Protection for HVAC and HVDC in wide area network control; Flexible AC Transmission Systems (FACTS); High power HVDC switchgear; New large power onshore connections; Innovative transport and installation methods both on and offshore.

In this paper, these systems will be analyzed in detail as well as some of possible applications. Particularly described is the supergrid concept as a way of transmitting "green energy". 


\section{DESCRITION OF HVDC SYSTEM}

The three main elements of the HVDC system are:

- Converter cells with the ends for sending and receiving,

- Portable brokers (overhead line or cabal) and

- Grounding electrodes.

Since converter stations can function as rectifiers and as inverters, it is possible to transfer electricity in both directions. HVDC is most commonly used for power transmission over long distances via cables and overhead lines. It is also used to connect asynchronous AC systems if they work on the same or different frequencies.

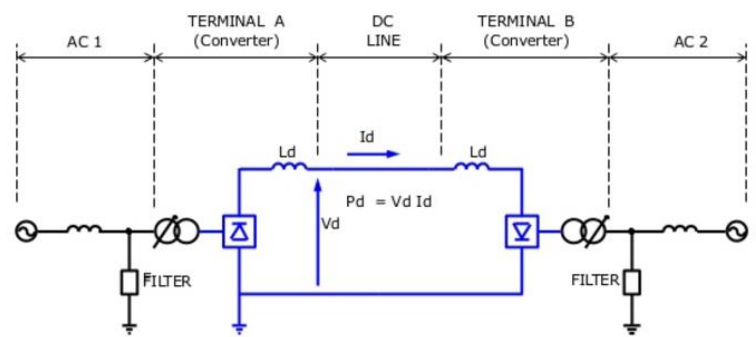

Fig. 1. Basic diagram of HVDC system.

The reasons for choosing HVDC are mostly economic, not technical. [1] [5] [6]

\section{Advantages and Disadvantages of HVDC}

HVDC systems advantages over AC transmission are as follows: Transfer of large amounts of electricity overhead lines; Transfer of large quantities of electricity through submarine cables; Fast and accurate control of the flow of electricity with HVDC lines to create a positive attenuation due to electromechanical oscillations and to improve network stability by means of modulation due to back-to-back transmission; Since the HVDC connection is not limited by the Phase and angle between two AC systems, it can be used to connect two systems with different frequencies using Asynchronous Back-to-Back; HVDC systems can also be used to connect renewable sources, and the best example are the wind farms where the production is located far away from consumers; VSC based on the HVDC technology gets more and more space. This technology is a result of the constant technology development of IGBT. In this system, PWM modulation can be used for VSC, versus thyristor used in HVDC systems; Since the reactive power is not transmitted by DC lines, two AC systems can be connected to DC lines without increasing the short circuit current.; back to back connections between systems of the same nominal frequency $(50 / 50 \mathrm{~Hz}$ or $60 / 60 \mathrm{~Hz})$; back to back connections between systems of different frequency $(50 / 60 \mathrm{~Hz})$; Multi-terminal connections with multiple rectifier and/or inverter station using the same transmission system; Multi-terminal connections with a tapping connection on the DC system.[1][5] [6] 


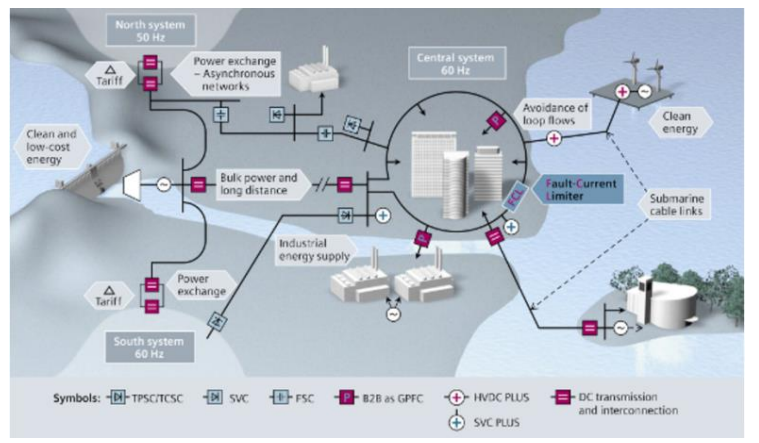

Fig. 2. Overview of HVDC system application [3]

Disadvantage of HVDC technology are: The disadvantage of HVDC is converter, switching, control, availability and maintenance; HVDC is less reliable and has lower availability than AC systems, mainly due to the extra conversion equipment; The required converter stations are costly and have limited overload capacity; At smaller transmission distances, the losses in converter station may be bigger than in an AC transmission line for the same distance; The main disadvantage of HVDC is the cost of equipment, primarily converter stations. It has a large number of thyristors, which are expensive components, and they lose a lot of energy during their work. At distances shorter than 350km HVDC technology becomes more expensive than HVAC technology. [2] [3] [5] [6]

\section{Types of HVDC Transmission}

There are two types of HVDC transmission: one pole and two pole. In the one-pole system, one end of the converter is a connected transmission line. This line is approximately at rated voltage, at a potential high above or below ground potential, depending on the course of the power flow. The other end is connected to grounding and it can, and does not have, to be connected by another conductor with the ground end of the second converter. The other conductor is practically on the potential of the ground. In single-pole HVDC systems, which exist almost exclusively in the form of submarine cable transmission systems, there are significant differences between the construction of cathode and anode electrodes used as grounders. The cathode operator is not exposed to its own electrolytic decomposition, and is most often performed by burial of several hundred meters of copper conductors of a large diameter in configuration of node or grid. Ground electrode in the role of the anode is exposed to an electrolytic degradation, so the anodic grounding is made of several meshes made of titanium. Modern monopolar systems for monitoring lines have a capacity of $1500 \mathrm{MW}$ of power transmission, while the capacity of submarine and underground cables up to $600 \mathrm{MW}$.

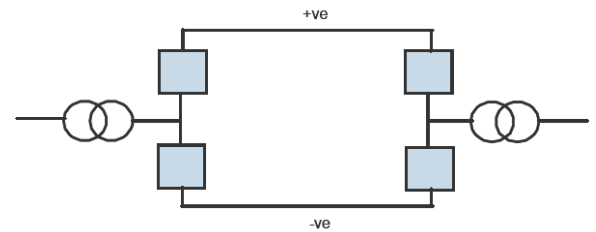

Fig. 3. Schematic of a symmetric monopole configuration 
Two-pole transmissions are used by a pair of conductors, each at high potential in relation to the ground, with the opposite polarity. By transferring one converter from rectifier to inverter, and neighboring converter voltage lines, and thus a change in the direction of power flow. The advantage of a two-pole transmission with embedded ground electrodes at each end comes to expression when defect develops at one of the leads. Then about half the rated energy will continue to flow using the ground for the path, in a one-pole mode of operation. [2] [5] [6].

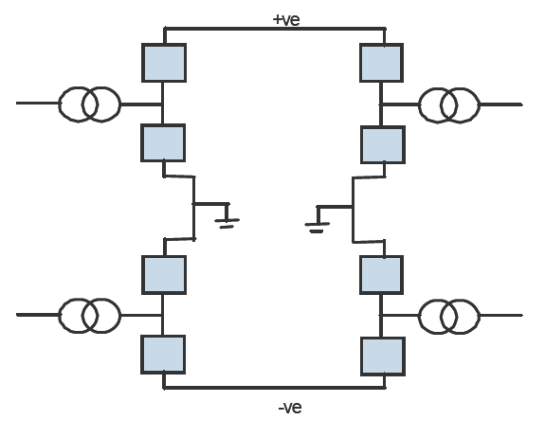

Fig. 4. Schematic of a bi-pole with ground/sea return

\section{DESCRIPTION OF CONVERTER STATIONS}

The most interesting part of HVDC systems are converter stations, which represent an innovative solution that has enabled the use of HVDC transmissions. The basic parts of the converter are inverters and transformers. The main part of the HVDC converter power is a semiconductor valve. The purpose of the transformer is to transform the AC system voltage to a specific AC voltage at the input of the inverter to obtain the corresponding DC voltage at the inverter. In addition to the thyristor and IGBT inverters and converter transformers, which are basic equipment, HVDC converter stations also contain AC filters, DC filters, DC chokes and disconnectors. There are two types of conversion, which are now in use. These are HVDC LCC (HVDC Transmission by using a network-switched converter) and HVDC VSC (HVDC transfer using power converter) [2] [5] [6].

\section{LCC HVDC}

LCC HVDC has been applied to the following types of power transmission:

- Submarine and underground cable transmission

- Asynchronous link between ac systems

- Long distance bulk power transmission using overhead lines

The standard bridge connection is a 6-pulse bridge converter that includes six powerful components, two in 3 branches. In today's HVDC systems, a 12 pulse converter is used.

Two fully rework able 6-pulse bridge converters are obtained as a serial link and require twophase systems that move each other for 30 electrical degrees. This requirement is achieved if two three-phase transformer transformers are used in different compounds, one in star-to-star coupling, and the other in star- triangle connector, as shown in Figure 5. In this way, both output voltages have been phase shifted for $30^{\circ}$. The control of both rectifiers is at the same time that at both outputs both pulsed voltages are shifted by $30^{\circ}$. Two AC voltages, phase shifted by $30^{\circ}$, are used to cancel the 5th and 7th harmonic currents on the $\mathrm{AC}$ side and 6th harmonic voltage on 
the DC side, resulting in significant savings on harmonic filter. Figure 5 shows a contour around each of the three groups of four components in one vertical line. They are known as "quadrivalves" and are composed as a thyristor structure created by binding four components in the series. Since the rated voltage for thyristors several $\mathrm{kV}$ in order "quadrivalves" (four valves) to withstand $500 \mathrm{kV}$, can have hundreds of independent (individual) thyristors with their control kits connected to serial groups [2] [5][6]

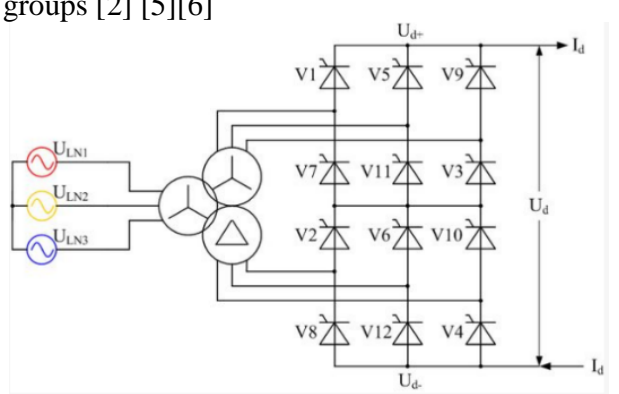

Fig. 5. 12-pulse bridge converter

\section{HVDC VSC}

If a HVDC transmission with a VSC converter is applied, a certain advantage over the system is given. The VSC converter can control the height of the active and reactive power separately, or independently, of one. Reactive power can also be controlled by the forward terminal, regardless of the DC voltage level. This capacity control provides comfort when it comes to the provision of converters to the AC network, as there is no limit to the provision of a minimum capacitive network connection in the network. The switching of the VSC itself enables a "black start", which would mean that the convertor generates a three-phase voltage system, as a virtual synchronous generator. Dynamic AC voltage support with a converter terminal enhances the stability of the voltage and can increase the transmission capability of receiving and receiving to the end of the AC system, thus aligning the forward capacities of the DC connection.

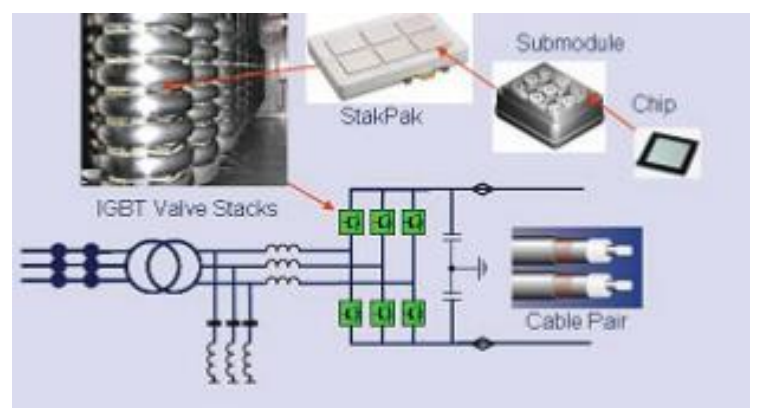

Fig. 6. Organization of the IGBT valve

The reactive power that appears in the HVDC system takes from the AC filters that monitor the capacitance at the base frequency, parallel or serial coupled capacitors, which are an integral part of the converter station. Whether the surplus or the reactive power deficit in the converter station must be covered from the AC system. This difference in the active force should be maintained at the limit values in order to keep the AC voltage in the range of nominal voltage tolerances. Figure 
7 shows the demand for reactive power, the compression of active forces and the exchange of reactive power with AC grid, in the function of DC load current, the VSC converter. Unlike nonconventional HVDC transmission, converters do not use reactive power and they actually control the active power by regulating the voltage in the AC system, just like the generators. [5][6]

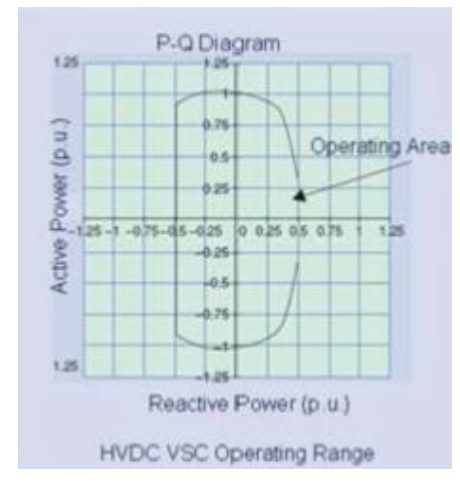

Fig.7.The range of active and reactive power

\section{The ways of connecting converter stations}

The three most important ways to connect converters are: Point to Point, Back to Back

Converter and Point-to-Point Multiterminal Transfer. It consists of a two-wire station interconnected by an overhead line or cable. Such systems are called still-dormant systems.

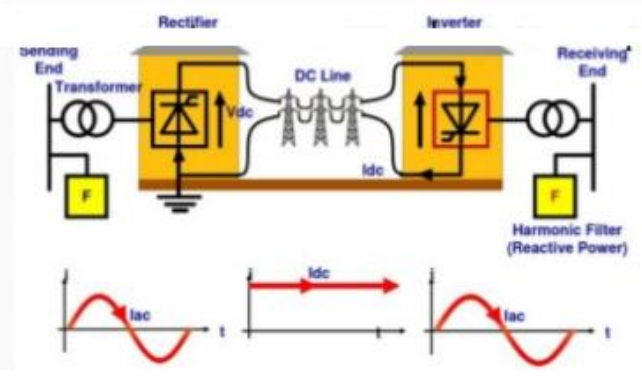

Fig. 8 Schematic of "point to point" transmission

The "Back to Back" converter contains no transmission line or cable to connect the adapter and inverter, but the timer is located in the same station. It finds application of linking three-phase networks whose nominal frequencies are different. 


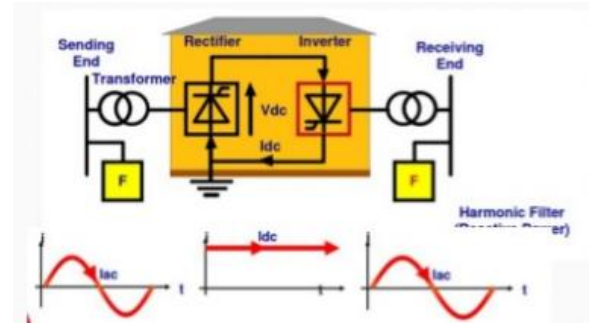

Fig. 9 The "Back to Back" scheme of the converter

When three or more HVDC converters, which are geodetic, connected to a portable overhead cable or HVDC cable, the transmission system is multi terminal. It can be a parallel or regular multi terminal system. [2][6]

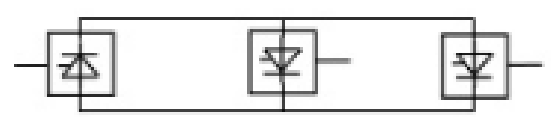

Fig. 10 Parallel multiterminal system

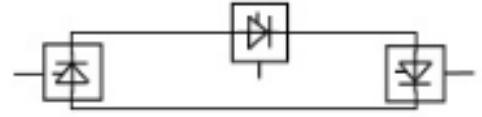

Fig. 11. Regular multiterminal system

\section{SUPERGRID}

In the North and Baltic Sea, and around the coast of Denmark, it has already been set up, and plans are being made to lift a number of dozens of GW wind farms. Their connection and transmission of generated electricity to consumers onshore is a great challenge for inventors and engineers. The first solutions led the application of HVDC transmission from the wind farm to the mainland. However, such a concept is not adequate for a large number of wind farms, so a new transmission system, called Supergrid, is designed with a vision to go around the European continent, aiming to connect future solar plants along the shores of the Mediterranean Sea and Sahara (Figure 12). Supergrid will be built in phases: the first offshore farms will now be connected to existing networks.

As a first step, Phase 1, super nodes in the North Sea will be built to collect the generated offshore energy for mass delivery. The Tenth GW Foundation project will be the first element of the Supergrid. It will consist of $10 \mathrm{GW}$ power plant. Energy obtained from wind power plants located in the North Sea between Great Britain, Netherlands and Germany. This project will link around 2000 wind turbines, covering an area of $3000 \mathrm{~km} 2$ with a capacity of 5MW for each turbine and an exit for all three countries.10 GW Foundation project will cost 2 million Euro / MW and the network is estimated at an additional 2 Billions euro's. The price of energy to be produced will be 77Evra / MWh in the first 25 years and only 48 Euro / MWh in the period from 26 to 50 years. Supergrid will use 70 percent capacity, while the wind power plant will have 40 percent of the connections. The $10 \mathrm{GW}$ project is sufficient to settle 8 million households with electricity. [4][6] 


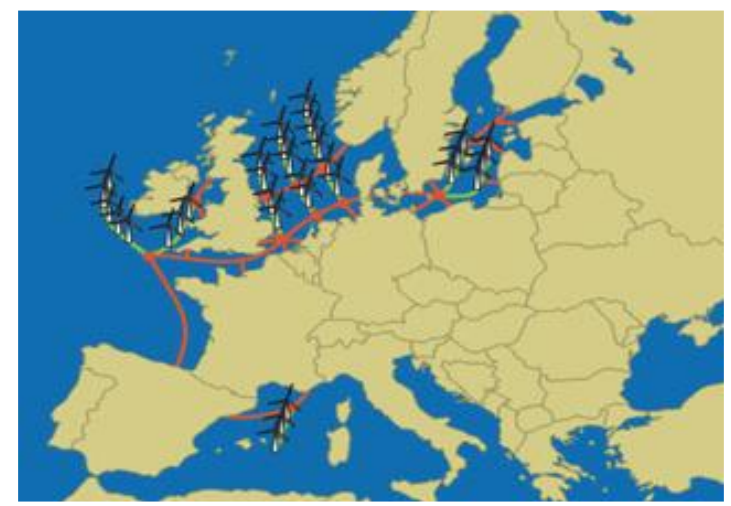

Fig. 12. Offshore Super grid

\section{Integration of Supergrid}

The challenge of matching an increasingly variable energy mix with the changing and variable load requires the integration of: Large scale interconnection (Supergrid), Forecasting and Demand Side Response (Smart Grid), Storage. [6]

\section{The Way to Develop Supergrid}

The decarbonisation of Europe's energy sector requires a strong integrated Supergrid. The development of such a grid can start today according to the installation of new renewable power plants. In principle, the entire Supergrid can be built by individual HVDC links that are interconnected via Supernodes. The most important step needed to develop HVDC grids further is the aspect of interoperability of different individual projects and technologies of different manufacturers. Interoperability requires standardization of the basic principles of design and operation of HVDC grids. As a starting point for the standardization of HVDC grids some fundamental planning criteria need to be defined, leading to different types of HVDC grids (e.g. transmission and distribution HVDC networks, sometimes also referred to as "local" and "inter area" grids). A Grid Code for the pan European Overlay Grid needs to be defined. Based on the fundamental planning criteria, important questions to be answered with respect to HVDC grid standardization include: Standardization of DC voltage levels; Concepts for interconnecting local and inter area DC grids probably with different DCvoltage levels; DC grid topologies; Control and protection principles; Fault behavior; Typical block sizes for converter stations.

Investors should be provided with clear guidelines on how to specify the equipment for a multi vendor HVDC grid. Such guidelines are normally summarized in functional specifications which are needed for, e.g.: AC/DC Converters; Cables; DC Overhead Lines; DC Chopper; Charging Resistors; DC Circuit Breakers; Communication for network control and protection. [4][6] 


\section{Market Scenarios for DC Grids}

The development of non-technical key issues outlined below will trigger or hold back the market evolution: International harmonization of grid codes and transmission investments; International harmonized regulatory procedures; Methods to share cross-border renewable subsidiary schemes; Multivendor and multi-stakeholder revenue models

In a pessimistic market scenario the development of these four issues will be slow during the next five years, implying that only regional DC can be planned, tendered, constructed and commissioned. New harmonization, support schemes and a Supergrid business model will be delayed until at least 2018. Consequently technology development will be slow. In the intermediate realistic scenario, new technical improvements will come continuously. In the optimistic market scenario during 2012-2027 the EU changes rules and regulations to promote formation of Supergrid. [4][6]

\section{Conclusions}

The working group has not identified any "show-stoppers" to the development of a European Supergrid. The VSC Transmission technology has already matured significantly during the last 15 years. For visionary long term planning of Transmission or Independent System Operators, the availability of key VSC-Grid technologies such as control and protection methods, main circuit design, grid master control, offshore operation experience and selective fault clearance techniques such as, dc breakers, can be assumed. This should give confidence to specify gridenabled point-to-point connections that could be expanded to multi-terminals building blocks for a larger overlaid grid. The critical time-line for introduction of new technology lies primarily in solution of non-technical issues that will create a strong market growth and technology push. An early solution of these hurdles will influence the future roadmap to a greater extent than may be foreseen, due to the extended time constants in planning and construction of new transmission capacity.

\section{References}

1. An Overview Introduction of VSC-HVDC: State-of-art and Potential Applications in Electric Power Systems, FENG WANG*, LINA BERTLING, TUAN LE, 21, rue d'Artois, F-75008 PARIS

2. HDVC Transmission, Dennis A. Woodford

3. https://www.energy.siemens.com/br/en/power-transmission/hvdc/applicationsbenefits/hvdc-applications.htm

4. http://www.elp.com/articles/powergrid_international/print/volume-21/issue12/features/the-rise-of-hvdc-and-promise-of-supergrids.html

5. https://www.pacw.org/issue/september_2016_issue/lessons_learned/hvdc_transmissio n_and_integration_into_an_ac_grid/complete_article/1.html

6. Roadmap to the Supergrid Technologies, Document prepared by FOSG WG 2 Technological, Frank Schettler, Maria-Sophie Balavoine, Magnus Callavik, Joe Corbett, Nikola Kuljaca, Vegar Syrtveit Larsen, Norman MacLeod, Björn Sonerud 